\title{
Cyclooxygenase- 2 is associated with malignant phenotypes in human lung cancer
}

\author{
WEIYING LI", WENTAO YUE* , HUI WANG, BAITANG LAI, XUEHUI YANG, \\ CHUNYAN ZHANG, YUE WANG and MENG GU \\ Department of Cellular \& Molecular Biology, Beijing Tuberculosis and Thoracic Tumor Research Institute, \\ Beijing Chest Hospital, Capital Medical University, Beijing 101149, P.R. China
}

Received April 10, 2015; Accepted July 12, 2016

DOI: $10.3892 / 01.2016 .5207$

\begin{abstract}
The objective of the present study was to investigate whether cyclooxygenase-2 (COX-2) is associated with malignancy, and to investigate its molecular mechanisms in human lung cancer tumor malignancy. The present study used RNA interference (RNAi) methodology and celecoxib, a COX-2 inhibitor, to investigate the effect of COX-2 knockdown on the proliferation and invasion abilities of lung cancer cells and the molecular mechanisms involved. Human lung adenocarcinoma A549-si10 and LTEP-A2 cells transfected with a specific small interfering RNA (A549-si10 and LTEP-A2-si10, respectively) grew more slowly compared with parental cell lines and cells transfected with pU6. The colony formation of A549-si10 and LTEP-A2-si10 cells was also reduced. In addition, A549-si10 and LTEP-A2-si10 cells were characterized by decreased metastatic and invasive abilities. The proliferation and invasive potential of parental A549 and LTEP-A2 cells was inhibited following treatment with celecoxib. In vivo, a COX-2 knockdown resulted in a decrease of proliferation and reduction of vascular endothelial growth factor (VEGF), matrix metalloproteinase-2 (MMP-2) and endothelial growth factor receptor (EGFR) expression in A549 xenografts. In conclusion, the present study revealed that COX-2 plays a extremely important role in tumor growth, infiltration and metastasis via the regulation of VEGF, MMP-2 and EGRF expression. Therefore, COX-2 is a potential therapeutic target for lung cancer.
\end{abstract}

Correspondence to: Dr Weiying Li, Department of Cellular \& Molecular Biology, Beijing Tuberculosis and Thoracic Tumor Research Institute, Beijing Chest Hospital, Capital Medical University, 97 Machang, Tongzhou, Beijing 101149, P.R. China

E-mail:1i_weiying412@aliyun.com

*Contributed equally

Key words: COX-2, lung cancer, malignant phenotype, celecoxib

\section{Introduction}

Lung cancer is one of the most common malignant tumors in the world. Its incidence rate the highest of all human tumors and there are $\sim 1.2$ million novel cases each year (1). In addition, lung cancer also has the highest mortality rate of all human cancers, with 15,600 people succumbing to the disease each year, which accounts for $19.4 \%$ of the total number of cancer-associated mortalities $(1,2)$. For $>80 \%$ of lung cancer patients admitted to hospital, the ideal time to receive surgery and multidisciplinary radical cure has already passed $(2,3)$. Although the concept and means of lung cancer treatment in recent years has made considerable progress, the overall effect is not satisfactory.

An association between carcinogenesis and chronic inflammation has long been suspected (4). The accepted hypothesis is that chronic inflammation more often stimulates than inhibits tumor development (5-9). As a rate-limiting enzyme, cyclooxygenase-2 (COX-2) is involved in the conversion of arachidonic acid into prostaglandin (PG) and other bioactive lipids. With the exception of being involved in inflammation, COX-2 produces large amounts of PGE2 in tumor tissues (10-13), and is extremely important in the development of tumors $(10,14-19)$. COX-2 inhibitors have produced encouraging results in preventing and treating certain digestive system cancers (20-22). The present study hypothesized that COX-2 is associated with malignant cell phenotype in lung cancer. Therefore, the present study investigated whether silencing of COX-2 and the use of celecoxib, an inhibitor of COX-2, affects lung cancer cell proliferation and invasiveness $(21,22)$. The present results demonstrated that silencing of COX-2 and use of celecoxib inhibited the growth of lung cancer cells and decreased their invasive abilities. In addition, the present results revealed that the inhibition of a malignant cell phenotype may be associated with an alteration in vascular endothelial growth factor (VEGF), matrix metalloproteinase (MMP)-2 and endothelial growth factor receptor (EGFR) expression.

\section{Materials and methods}

Cell culture. Human lung adenocarcinoma A549 and LTEP-A2 cells were purchased from the Cell Center of 
Peking Union Medical College (Beijing, China). The cells were cultured in RPMI-1640 medium (Gibco ${ }^{\circledR}$; Thermo Fisher Scientific, Inc., Waltham, MA, USA) supplemented with $10 \%$ fetal bovine serum (FBS; Gibco ${ }^{\circledR}$ ), $100 \mathrm{U} / \mathrm{ml}$ of penicillin and $100 \mathrm{U} / \mathrm{ml}$ of streptomycin in a humidified $37^{\circ} \mathrm{C}$ incubator with $5 \% \mathrm{CO}_{2}$.

RNA interference (RNAi) vector transfection. The specific RNAi vector psi10 and empty vector pU6 were constructed in a previous study, in which the construction process and the interference effect of the vectors were observed (23). In total, $3 \times 10^{5}$ cells were seeded into $35 \mathrm{~mm}$ culture plates. When the cells were $70-80 \%$ confluent, the cells were transfected with plasmids (pU6 and psi10) using Lipofectamine 2000 (Invitrogen $^{\mathrm{TM}}$; Thermo Fisher Scientific, Inc.), according to the manufacturer's protocol. Complete RPMI-1640 medium supplemented with geneticin $(800 \mu \mathrm{g} / \mathrm{ml})$ was used to screen the clones. The transfected A549 and LTEP-A2 cell strains were named A549-pU6, A549-si10, LTEP-A2-pU6 and LTEP-A2-sil0.

Western blotting. Protein was extracted using conventional protocols (9 M urea, 4\% 3-[(3-cholamidopropyl) dimethylammonio]-1-propanesulfonate, $1 \%$ dithiothreitol, $0.5 \%$ carrier ampholytes and cocktail of protease inhibitors). Protein concentrations were determined using Pierce ${ }^{\mathrm{TM}}$ BCA Protein Assay kit (Thermo Fisher Scientific, Inc.) with bovine serum album as a standard. Subsequently, proteins were separated on $12 \%$ polyacrylamide gels using standard sodium dodecyl sulfate-polyacrylamide gel electrophoresis techniques and then transferred to nitrocellulose membranes. The membranes were blocked by $5 \%$ milk (Invitrogen; Thermo Fisher Scientific, Inc.) for $1 \mathrm{~h}$ and probed with specific antibodies for $4^{\circ} \mathrm{C}$ overnight. Mouse anti-COX-2 polyclonal antibodies (dilution, $1 \mu \mathrm{g} / \mathrm{ml}$; catalog no., 3362R-100; BioVision, Inc., Milpitas, CA, USA) were used, and mouse anti-glyceraldehyde 3-phosphate dehydrogenase monoclonal antibodies (dilution, $0.3 \mathrm{ng} / \mu \mathrm{l}$; catalog no., 60004-1-Ig; ProteinTech Group, Rosemont, IL, USA) were used as an internal reference. After three washing steps of 15 min each with Tris-buffered saline and Tween (TBST), the membranes were probed with horseradish peroxidase-conjugated goat anti-mouse $\operatorname{IgG}$ antibodies (dilution, 1:5,000; catalog no., sc-2005; Santa Cruz Biotechnology, Inc., USA) at $37^{\circ} \mathrm{C}$ for $1 \mathrm{~h}$. After three washing steps of 15 min each with TBST, the protein was tested by chemiluminescence detection (catalog no., 29100; Engreen Biosystem Co., Ltd., Beijing, China). The protein expression was analyzed by Image-Pro Plus 6.0 software (Media Cybernetics, Inc., Rockville, MD, USA).

Cell growth curve assays. Tumor cells (3,000 cells/well) were seeded in flat-bottom 96-well plates. Cell activity was assessed by a 3-(4,5-dimethyl-thiazol-2yl)-5-(3-carboxymethoxyphen yl)-2-(4-sulfophenyl)-2H-tetrazolium (MTS) assay (Promega, Madison, WI, USA). The growth of cells was detected for 5 days. Subsequently, $20 \mu$ MTS was added into each well and then incubated with the cells for $3 \mathrm{~h}$. The absorbance was recorded at $490 \mathrm{~nm}$ with an ELx800 Absorbance Reader (Bio-Tek Instruments, Winooski, VT, USA). This experiment was repeated three times.
Colony formation assays. A total of 300 cells were seeded in 6-well plates. The cells were cultured for 10 days. On the 10th day, the number of colonies with $>50$ cells was recorded using the trypan blue exclusion method. The experiment was repeated three times in triplicate.

Cell migration assay. Cell motility was evaluated by two experiments. In the wound healing experiment, channels were created by making a scratch in a 6 -well plate. Subsequently, $8 \times 10^{5}$ cells per channel were seeded into the 6 -well plates and cultured for $24 \mathrm{~h}$. At 0,12 and $24 \mathrm{~h}$, the wounds were observed and pictures were taken using a phase-contrast microscope. The areas of the scratch were calculated using Alpha View Analysis Tools version 1.0 software (ProteinSimple, San Jose, CA, USA), and this was used to calculate the percentage of wound closure.

In addition, a migration experiment was performed in a 24-well Transwell unit (Corning, Inc., Corning, NY, USA), as previously reported (24). The cells were starved for $12 \mathrm{~h}$ and $8 \times 10^{5}$ cells were seeded in the upper compartment of the Transwell unit with serum-free medium. The lower compartment was filled with medium containing $10 \%$ FBS. Subsequent to 24 or $48 \mathrm{~h}$, the cells in the upper chamber were removed by gentle swabbing. The number of cells migrating to the lower surface of the membrane was determined using crystal violet. Five microscopic fields were randomly selected and viewed at x200 magnification. Three repeats were performed.

Invasion assay. Cell invasion was analyzed using Boyden chambers polyvinylpyrrolidone-free polycarbonate filters (8 $\mu \mathrm{m})$ coated with $5 \mu \mathrm{g} / \mathrm{ml}$ Matrigel (BD Biosciences, Franklin Lakes, NJ, USA). The cells were starved for $12 \mathrm{~h}$ and $2 \times 10^{6}$ cells were seeded in the upper compartment of the Transwell unit with serum free medium. The lower compartment was filled with medium containing $10 \%$ FBS. The filters were stained with crystal violet solution. Crystal violet stained invading cells were viewed at x400 magnification. For each filter, cells in 10 randomly chosen fields were counted and expressed as the number of invading cells per high-power field.

COX-2 inhibitor celecoxib functional studies. Cell proliferation, migration and invasion assays were also evaluated in the presence of celecoxib (Selleck, Houston, TX, USA). Briefly, A549 and LTEP-A2 cells were incubated in 96-well plates or 6-well plates with celecoxib $(45 \mu \mathrm{g} / \mathrm{ml})$ for $3 \mathrm{~h}$. Dimethyl sulfoxide $(0.3 \mu \mathrm{l} / \mathrm{ml})$ was used as a control.

Tumor growth in nude mice. The mice used in the present study were 4-week-old male BALB/c nude mice (Vital River Laboratories Co., Ltd, Beijing, China). The average weight of the mice was $17 \mathrm{~g}$. Each group included 6 mice. Nude mice were raised in a specific pathogen-free level room and all feed was sterilized. The housing was maintained at a temperature of $26-28^{\circ} \mathrm{C}$. The relative humidity was maintained at $40-60 \%$. The daily light/dark cycle consisted of $10 \mathrm{~h}$ of light and $14 \mathrm{~h}$ of dark. All animal experiments and maintenance were approved by the Ethics Committee of the Beijing Chest Hospital, Capital Medical University, Beijing, China, and conformed to the guidelines of the Animal Care and Use Committee and the Chinese Association of Laboratory Animal Care. 

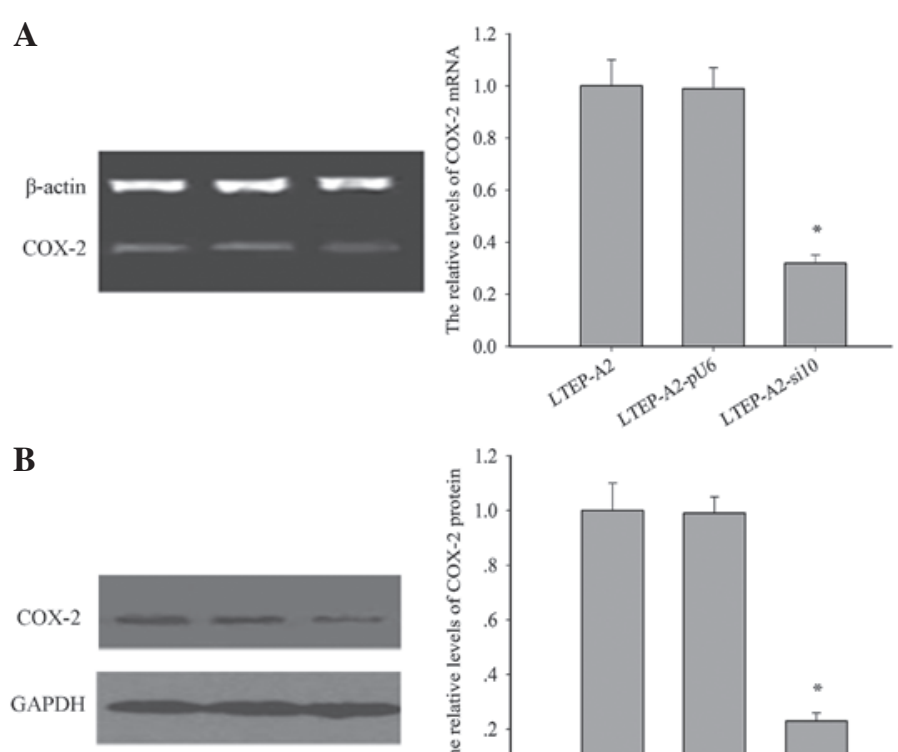
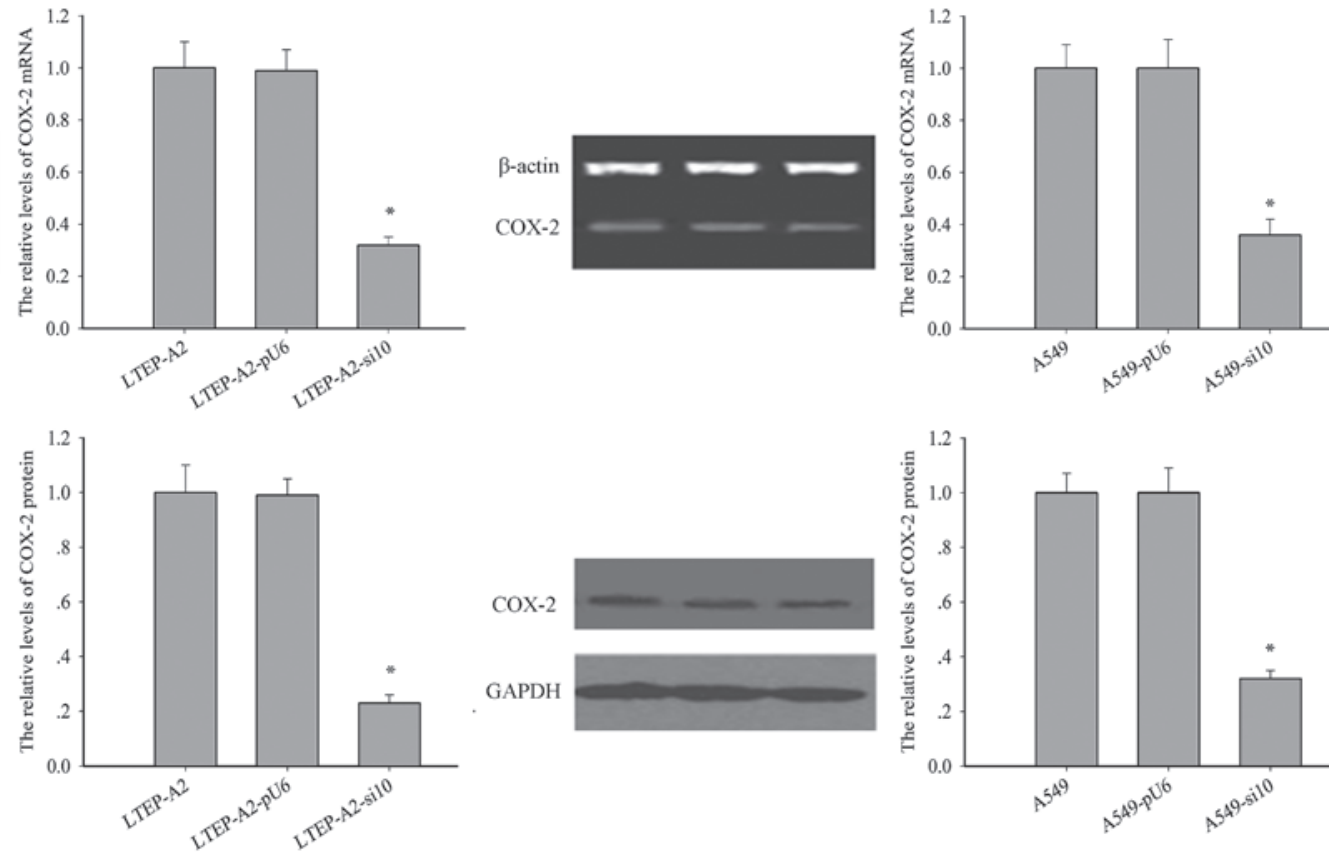

Figure 1. COX-2 expression in transfected cells. (A) mRNA (left and right panel, $* \mathrm{P}=0.032$ and 0.036 ) and (B) protein expression (left and right panel, $* \mathrm{P}=0.021$ and 0.029, respectively) of COX-2 in human lung adenocarcinoma LTEP-A2 and A549 cells transfected with si10 and pU6. COX-2, cyclooxygenase-2; si10, small interfering RNA against COX-2.

A549, A549-pU6 and A549-si10 cells were collected and resuspended in $10 \%$ RMPI-1640 at a density of $1.5 \times 10^{7}$ cells $/ \mathrm{ml}$. In total, $3 \times 10^{6}$ cells were injected subcutaneously into the flanks of 4-week-old male BALB/c nude mice. The date at which a palpable tumor first arose was recorded. On the 60th day following tumor injection, the mice were euthanized using a standard carbon dioxide method, and tumors were harvested and weighed.

Immunohistochemistry. For immunohistochemistry, $4-\mu \mathrm{m}$-thick tumor sections were immersed in $0.3 \%$ hydrogen peroxide for $10 \mathrm{~min}$, microwaved in citrate phosphate buffer (pH 6.0) and incubated with 10\% normal goat serum (Maixin Biotech. Co., Ltd., Fuzhou, China) for $30 \mathrm{~min}$. The tumor slices were incubated overnight at $4^{\circ} \mathrm{C}$ with the following primary monoclonal antibodies (Maixin Biotech. Co., Ltd.): Rabbit anti-COX-2 monoclonal antibodies (catalog no., RMA-0549); mouse anti-MMP-2 monoclonal antibodies (catalog no., MAB-0244); and mouse anti-VEGF monoclonal antibodies (catalog no., MAB-0243). Secondary anti-mouse/rabbit antibodies from Kit-5030 (Maixin Biotech. Co., Ltd.) were then incubated with the samples at $37^{\circ} \mathrm{C}$ for $15 \mathrm{~min}$. Primary and secondary antibodies were working solution and were not diluted. A standard staining procedure was finished by using a 3,3'-diaminobenzidine kit (Kit-0014; Maixin Biotech. Co., Ltd.). Immunostaining was evaluated blindly by a board-certified pathologist (Capital Medical University), who assigned the intensity and prevalence score as described previously (25). Five microscopic fields were randomly selected and viewed at a magnification of $x 100$. Briefly, the intensity of staining was scored as follows: 0 , negative; 1 , weak staining; 2 , moderate staining; and 3 , strong staining.

Statistical analysis. All statistical analyses were performed using SPSS version 13.0 software (SPSS, Inc., Chicago,
IL, USA). Quantitative variables were compared using the one-way analysis of variance. The $\chi^{2}$ test was used to assess qualitative variables. $\mathrm{P}<0.05$ was considered to indicate a statistically significant difference.

\section{Results}

Reduced expression of COX-2 in RNAi transfected cell lines. The levels of COX-2 protein and mRNA were examined in the transfected lines (Fig. 1A and B). Following RNAi transfection, the expression level of COX-2 was significantly reduced in LTEP-A2-si10 and A549-si10 cells. Compared with the parental cells, the levels of COX-2 mRNA were reduced by $60.0 \%(\mathrm{P}=0.005)$ and $62.1 \%(\mathrm{P}=0.004)$ and $\mathrm{COX}-2$ protein by $68.2 \%(\mathrm{P}=0.002)$ and $75.3 \%(\mathrm{P}=0.001)$ in $\mathrm{A} 549$-si10 and LTEP-A2-si10 cells, respectively.

Altered proliferation rates of LTEP-A2 and A549 cells due to knockdown of COX-2 in vitro. To determine the result of silencing COX-2, cell proliferation and colony formation assays were performed. As indicated in Fig. 2A, the growth of LTEP-A2-si10 cells was reduced on the third day. On the fourth and fifth day, proliferation of LTEP-A2-si10 cells was considerably reduced compared with parental cells $(\mathrm{P}=0.037)$. Similarly, proliferation of A549-si10 cells was clearly reduced compared with parental cells $(\mathrm{P}=0.041)$. To further confirm these results, a COX-2 inhibitor, celecoxib, was used to inhibit COX-2 expression and revealed that COX-2 inhibition plays a role in cell proliferation. COX-2 expression was clearly reduced by $89.5(\mathrm{P}=0.045)$ and $87.5 \%$ $(\mathrm{P}=0.043)$ in A549 and LTEP-A2 cells, respectively, when $45 \mu \mathrm{g} / \mathrm{ml}$ celecoxib was used (Fig. 2B). Therefore, $45 \mu \mathrm{g} / \mathrm{ml}$ celecoxib was used in following experiments. An MTS assay was performed, which demonstrated that the proliferation 
A

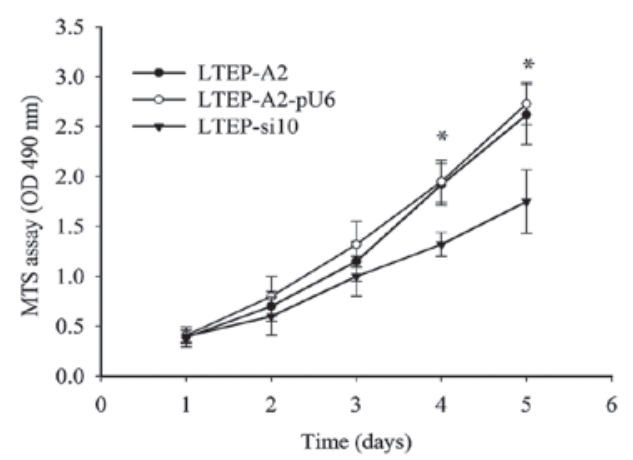

B

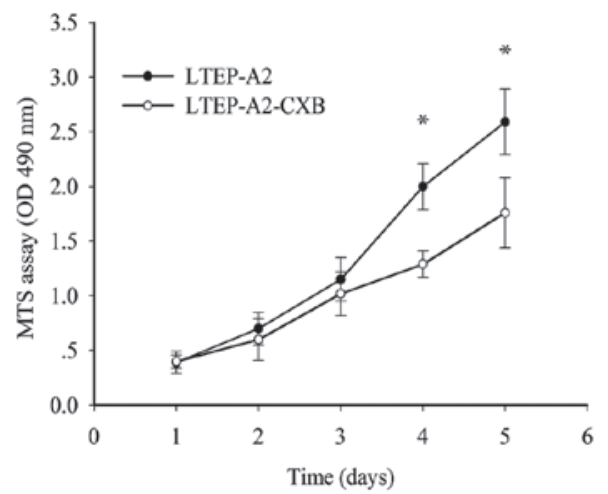

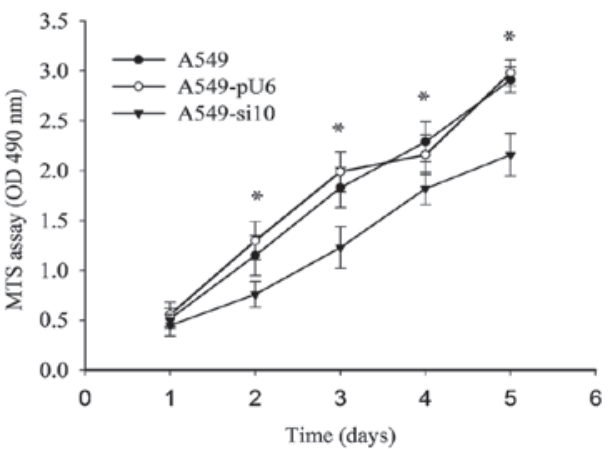

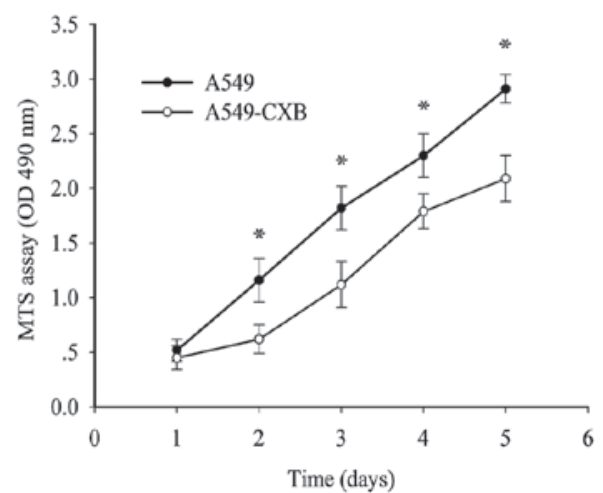

Figure 2. Cell growth assays in transfected cells and cells treated with CXB. (A) Cell growth curves of human lung adenocarcinoma LTEP-A2 ("P=0.037) and A549 ("P=0.041) cells transfected with si10 and pU6. " $\mathrm{P}<0.05$ vs. parental cells. (B) Cell growth curves of LTEP-A2 ("P=0.043) and A549 ("P=0.045) parental cells treated with $45 \mu \mathrm{g} / \mathrm{ml}$ CXB. CXB, celecoxib; si10, small interfering RNA against cyclooxygenase-2; MTS, 3-(4,5-dimethyl-thiazol-2yl)-5-(3-carboxyme thoxyphenyl)-2-(4-sulfophenyl)-2H-tetrazolium; OD, optical density.
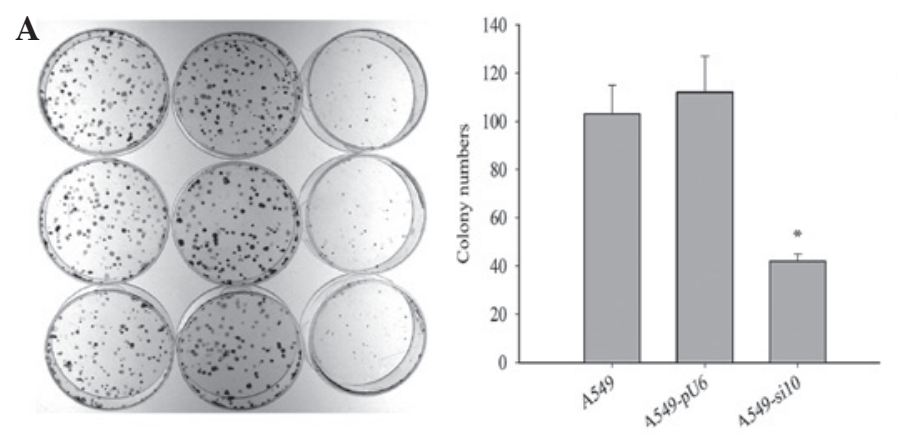

B
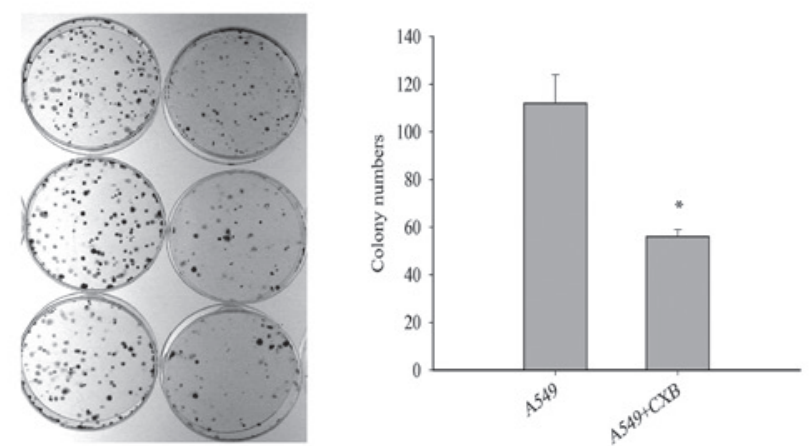
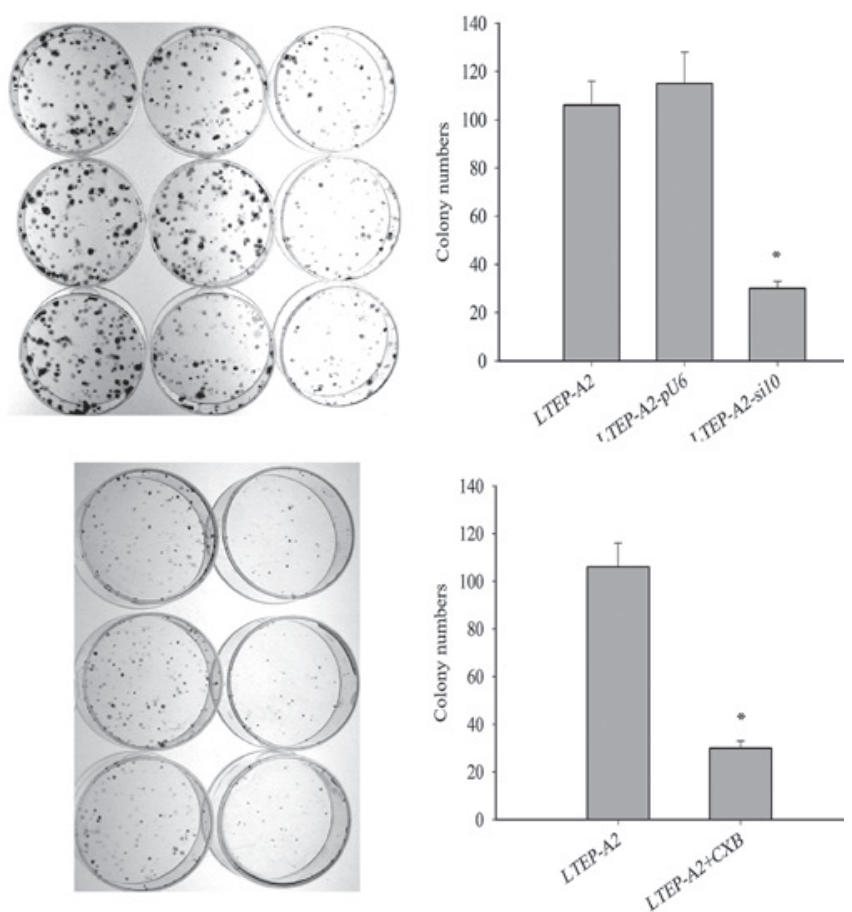

Figure 3. Colony formation assays in transfected cells and cells treated with CXB. (A) Colony formation assays of human lung adenocarcinoma LTEP-A2 (" $\mathrm{P}=0.026$ ) and $\mathrm{A} 549$ (" $\mathrm{P}=0.021$ ) cells transfected with si10 and pU6. (B) Colony formation assays of LTEP-A2 ("P=0.043) and A549 (" $\mathrm{P}=0.019)$ parental cells treated with $45 \mu \mathrm{g} / \mathrm{ml}$ CXB. CXB, celecoxib; si10, small interfering RNA against cyclooxygenase-2.

ability of A549 and LTEP-A2 cells was similar to A549-si10 and LTEP-A2-si10 cells following treatment with celecoxib (Fig. 2B).
Cell tumorigenisis was inhibited following suppression of $C O X-2$. To investigate the effect of COX-2 on tumor growth, cell tumorigenesis was evaluated by colony formation assay. 
Table I. Growth of mouse xenografts from human lung adenocarcinoma A549 and LTEP-A2 cells transfected with pU6 and si10.

\begin{tabular}{|c|c|c|c|c|c|c|c|}
\hline \multirow{2}{*}{$\begin{array}{l}\text { Groups } \\
\text { A549 }\end{array}$} & \multicolumn{6}{|c|}{ Tumor weights, $\mathrm{g}$} & \multirow{2}{*}{$\begin{array}{c}\text { Average tumor weight, } g \\
0.37 \pm 0.17\end{array}$} \\
\hline & 0.55 & 0.30 & 0.30 & 0.10 & 0.55 & 0.40 & \\
\hline A549-pU6 & 0.35 & 0.60 & 0.20 & 0.15 & 0.15 & 0.35 & $0.30 \pm 0.17$ \\
\hline A549-si10 & 0.20 & 0.30 & 0.05 & 0.05 & 0.20 & 0.00 & $0.13 \pm 0.11^{\mathrm{a}}$ \\
\hline
\end{tabular}

${ }^{\mathrm{a}} \mathrm{P}=0.008$ vs. A549 and A549-pU6 xenografts. si10, small interfering RNA against cyclooxygenase-2.

A

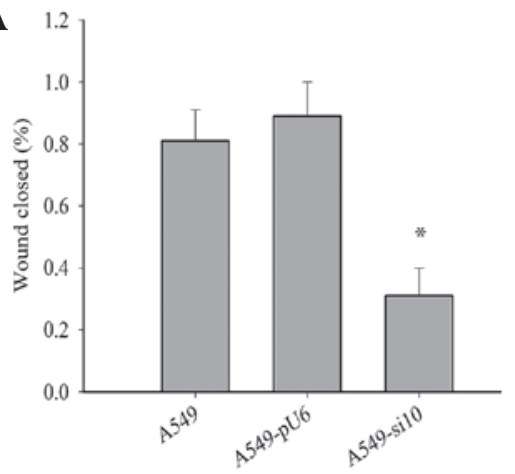

B

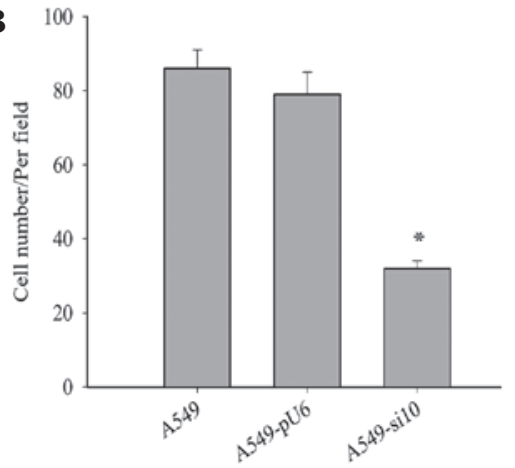

C

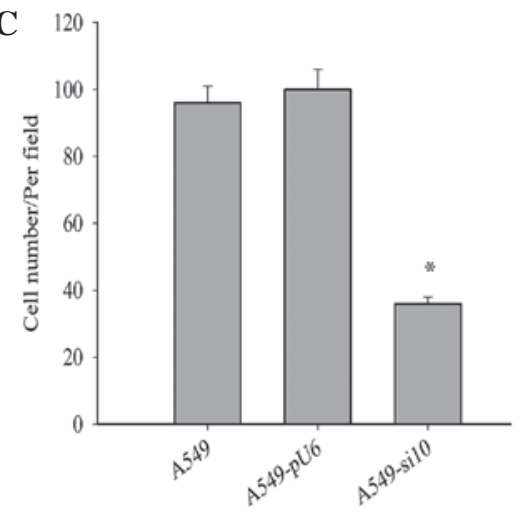

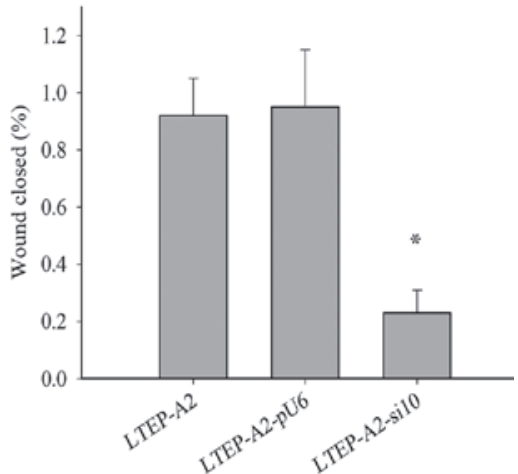
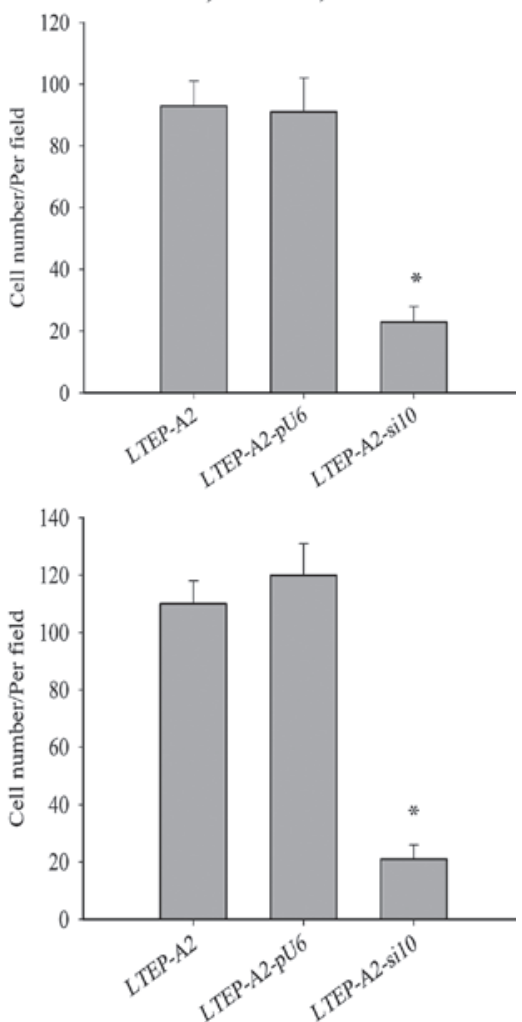

Figure 4. Wound healing, invasion and migration Transwell assays in transfected cells. (A) Wounding healing (left and right panel, ${ }^{*} \mathrm{P}=0.036$ and 0.027 , respectively), (B) invasion Transwell (Matrigel) (left and right panel, ${ }^{*} \mathrm{P}=0.032$ and 0.028 , respectively) and (C) migration Transwell (without Matrigel) (left and right panel, ${ }^{*} \mathrm{P}=0.033$ and 0.019 , respectively) assays of human lung adenocarcinoma LTEP-A2 and A549 cells transfected with si10 and pU6. si10, small interfering RNA against cyclooxygenase-2.

The colony formation rates of A549-si10 $(\mathrm{P}=0.021)$ and LTEP-A2-si10 $(\mathrm{P}=0.026)$ cells were significantly reduced compared with the parental cells after 10 days (Fig. 3A). This suggests that COX-2 may overcome the density-dependent inhibition of growth in tumor cells. When celecoxib was used, the colony formation rates of parental A549 $(\mathrm{P}=0.019)$ and LTEP-A2 $(\mathrm{P}=0.043)$ cells were significantly reduced compared with the control cells after 10 days (Fig. 3B).

Cell metastasis was decreased by COX-2 suppression. Metastasis is a major characteristic of cancer cells. To further study the effect of COX-2 on LTEP-A2 and A549 cell metastasis, 

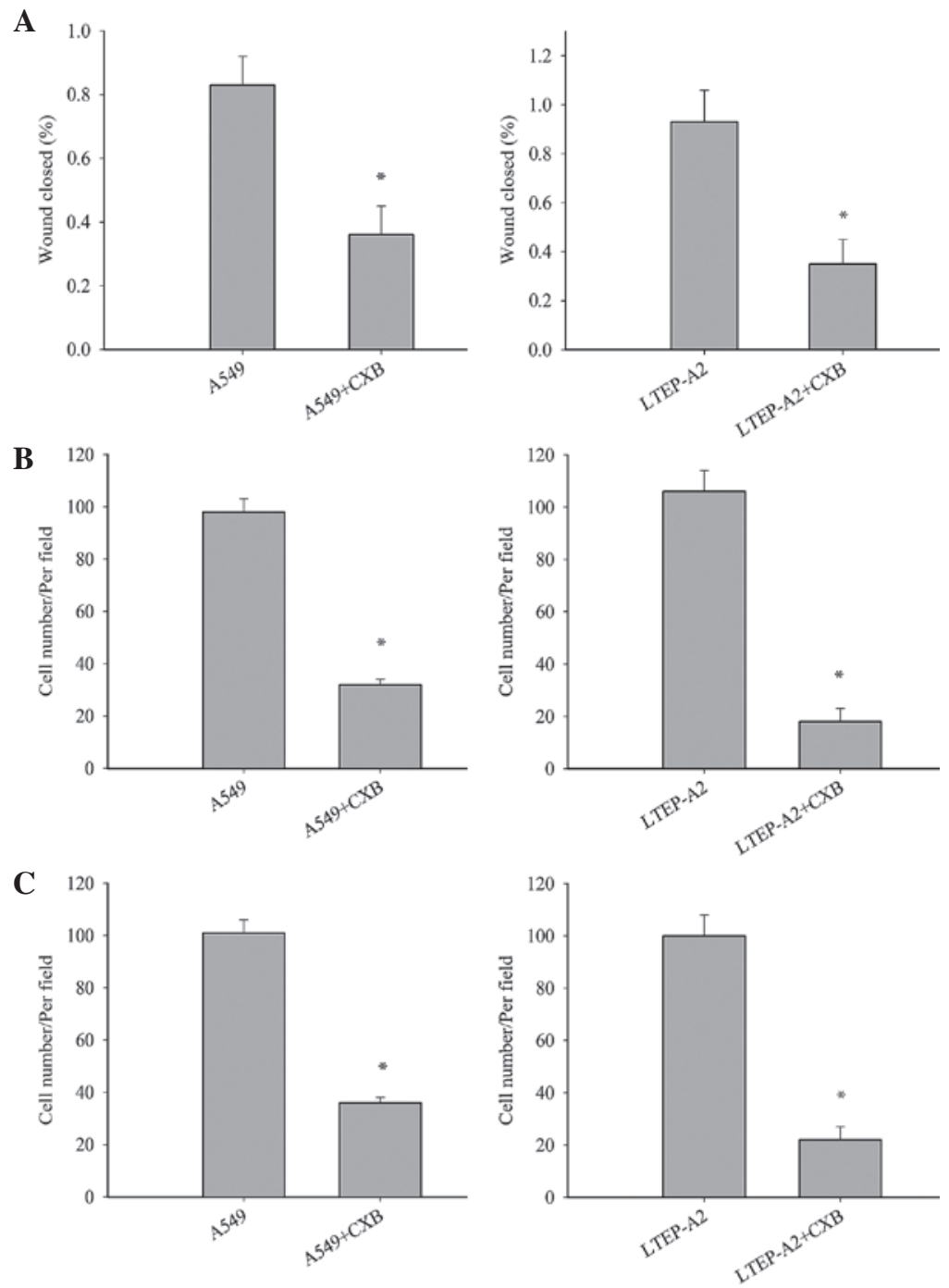

Figure 5. Wound healing, invasion and migration Transwell assays in cells treated with CXB. (A) Wounding healing (left and right panel, " $\mathrm{P}=0.039$ and 0.035 , respectively), (B) invasion Transwell (Matrigel) (left and right panel, ${ }^{*} \mathrm{P}=0.026$ and 0.021 , respectively) and (C) migration Transwell (without Matrigel) (left and right panel, ${ }^{\mathrm{P}} \mathrm{P}=0.028$ and 0.020 , respectively) assays of human lung adenocarcinoma LTEP-A2 and A549 cells treated with CXB. ${ }^{*} \mathrm{P}<0.05$ vs. cells not treated with CXB. CXB, celecoxib.

the present study examined its effect on cell migration and invasion. Wound healing (Fig. 4A), invasion (Fig. 4B) and migration (Fig. 4C) were inhibited in A549-si10 ( $\mathrm{P}=0.036$, 0.033 and 0.032 , respectively) and LTEP-A2-si10 ( $\mathrm{P}=0.027$, 0.019 and 0.028 , respectively) cells compared with parental control cells. When parental cells were treated with celecoxib, the cell migration and invasion of A549 and LTEP-A2 cells were significantly reduced compared with the control groups after 10 days (Fig. 5). These results reveal that COX-2 may promote tumor cell metastasis.

Tumor growth in vivo was slowed by COX-2 suppression. Tumor growth of mouse xenografts was substantially slowed following COX-2 treatment compared with control groups (Table I). Tumors developed three weeks following inoculation: 6 tumors in A549 group; 4 tumors in A549-pU6 group; 1 tumor in A549-si10 group. In the fourth week, there were 6 tumors in A549 group, 6 in A549-pU6 group and 3 in the A549-si10 group. By the 45th day, there were 6 tumors in A549 group, 6 in A549-pU6 group, and 5 in A549-si10 group.
VEGF, MMP-2 and EGFR expression was downregulated following COX-2 suppression in vivo. The expression levels of COX-2 were primarily evaluated in tumor tissues excised from the mice xenografts. The findings were consistent with those in vitro (data not shown). COX-2 expression in A549 and A549-pU6 xenografts was moderately positive and scored 2, but this was clearly reduced in A549-si10 xenografts, which were weakly positive and scored 1 (Fig. 6A). The expression of VEGF, MMP-2 and EGFR in A549-si10 xenografts was clearly reduced compared with A549 and A549-pU6 (Figs. 6B, C and 7A). The expression of hypoxia-inducible factor- $\alpha$ and MMP-9 in A549-si10 xenografts did not clearly alter compared with A549 and A549-pU6 (Fig. 7B and C).

\section{Discussion}

Recently, numerous studies have demonstrated that COX-2 is not only involved in tumorigenesis and tumor development, but also plays a role in inflammation (26-28). In tumor tissues, overexpression of COX-2 is a common phenomenon. Previously published results of the associations between 
A
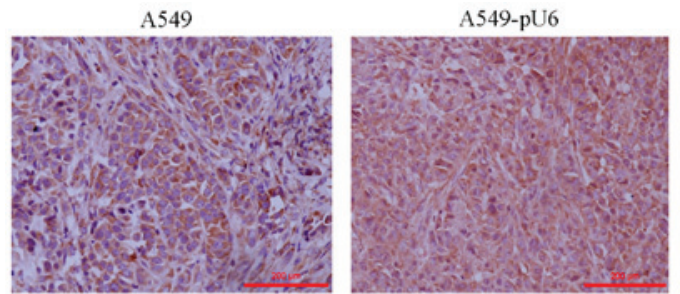

B

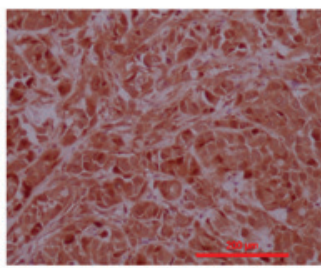

C

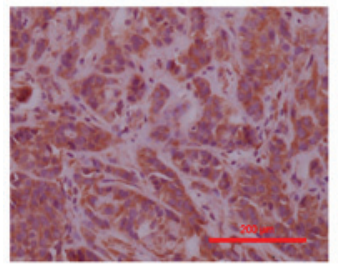

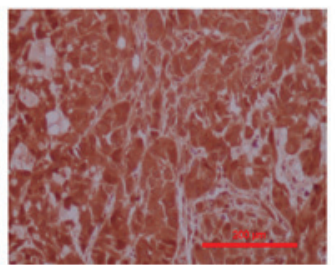

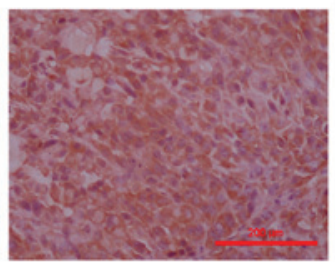

A549- si10
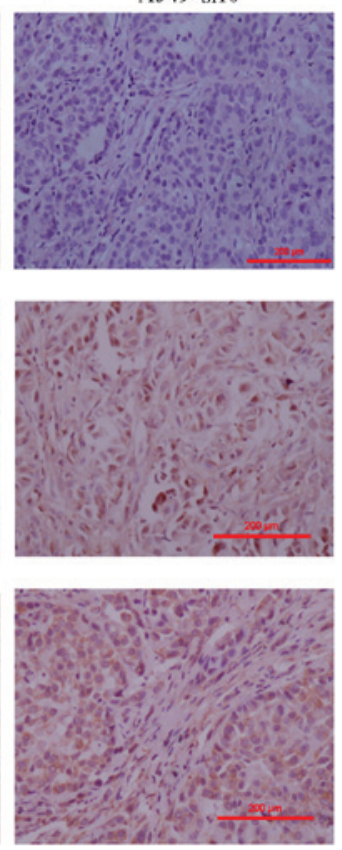

Figure 6. Immunohistochemistry of mouse xenografts from human lung adenocarcinoma A459 cells transfected with si10 and pU6 (magnification, x100). (A) Intensity of COX-2 expression staining was scored in the xenografts as follows: A549, 1; A549-pU6s, 1; A549-si10, 0. (B) Intensity of matrix metalloproteinase-2 expression staining was scored in the xenografts as follows: A549, 3; A549-pU6, 3; A549-si10, 1. (C) Intensity of vascular endothelial growth factor expression staining was scored in the xenografts as follows: A549, 2; A549-pU6, 2; A549-si10, 1. Scale bar, $200 \mu \mathrm{m}$. COX-2, cyclooxygenase-2; si10, small interfering RNA against COX-2.

A

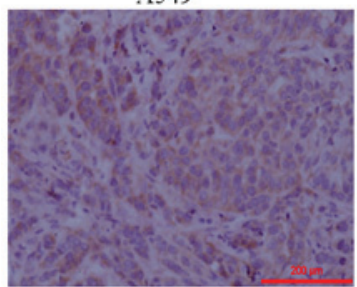

B

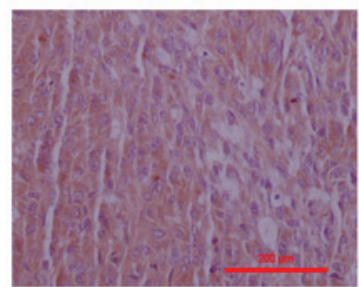

$\mathbf{C}$

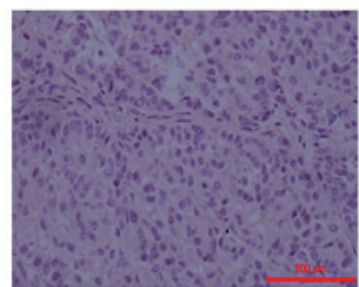

A549-pU6
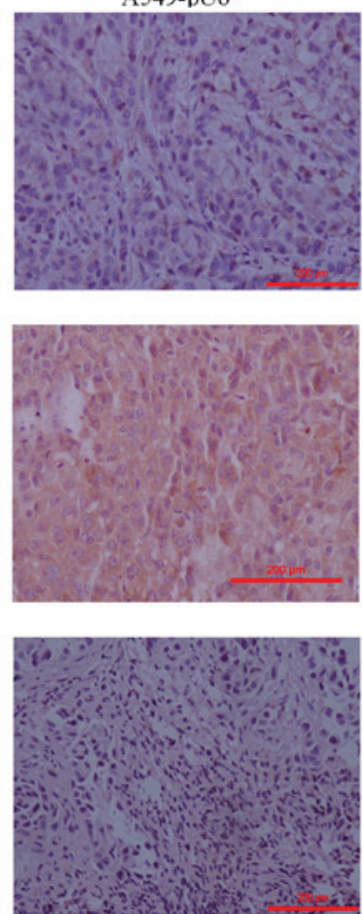

A549- sil0
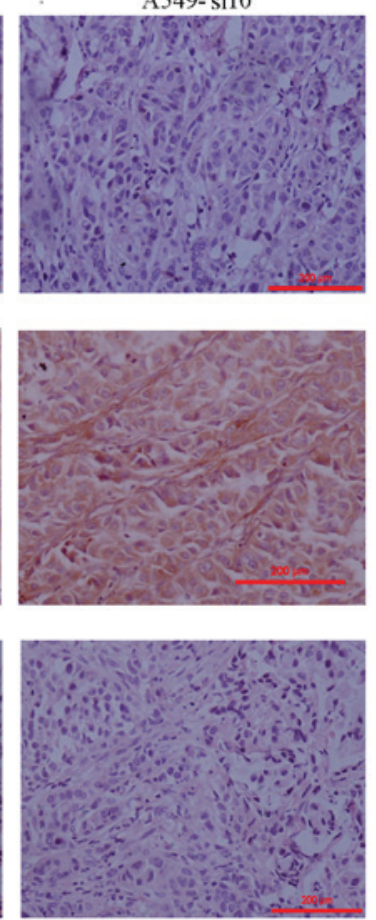

Figure 7. Immunohistochemistry of mouse xenografts from human lung adenocarcinoma A459 cells transfected with si10 and pU6 (magnification, x100). (A) Intensity of epidermal growth factor receptor expression staining was scored in the xenografts as follows: A459, 1; A459-pU6, 1; A459-si10, 0. (B) Intensity of matrix metalloproteinase-9 expression staining was scored in the xenografts as follows: A549, 2; A549-pU6, 2; A549-si10, 2. (C) Intensity of hypoxia-inducible factor- $\alpha$ expression staining was scored in the xenografts as follows: A549, 0; A549-pU6, 0; A549-si10, 0. Scale bar, $200 \mu$ m. si10, small interfering RNA against cyclooxygenase-2.

COX-2 and clinicopathological factors are not consistent for lung cancer $(19,29-31)$. Our previous results demonstrated that COX-2 was associated with malignant pathology, tumor-node-metastasis stage, lymph node metastasis, degree of differentiation and smoking (32). These results are also supported by the literature (29-31). 
Since COX-2 is associated with numerous clinicopathological parameters, it may be extremely important in the occurrence and development of lung cancer. To confirm this hypothesis, the present study used RNAi technology to investigate whether interfering with COX-2 expression affects lung cancer cell proliferation and invasion. The present results revealed that COX-2 knockdown significantly slowed the proliferation and invasion of LTEP-A2 and A549 lung cancer cells. In mouse xenografts, tumor growth was slowed following silencing of COX-2, which further confirmed our hypothesis. In addition, the present results demonstrated that silencing COX-2 in lung cancer cells inhibited cell proliferation and increased cell sensitivity to density-dependent inhibition. This is consistent with previous studies $(33,34)$. Notably, COX-2 knockdown clearly inhibited cell migration and invasion, suggesting that COX-2 has an important effect on the metastasis of non-small cell lung cancer (NSCLC) cells (35-37). The present results indicate that COX-2 plays a key role in the proliferation, motility and invasion of lung cancer cells. In order to further confirm the role of COX-2 in tumorigenesis and development, a COX-2 inhibitor, celecoxib, was used by the present study in migration, invasion and proliferation assays, which had similar results compared with COX-2 interference.

Subsequently, the present study investigated the molecular mechanisms by which COX-2 is key in tumor malignancy. The expression of COX-2 was primarily detected in mouse xenografts to verify the changes following the silencing of COX-2. Since, COX-2 is associated with proliferation, migration and vascular lumen formation of endothelial cells $(23,28)$, VEGF, MMP-2, MMP-9 and EGFR were investigated by the present study. The expression of MMP-2, VEGF and EGFR was clearly reduced following silencing of COX-2. MMP is a protein that degrades the extracellular matrix $(38,39)$, and previous studies have verified the involvement of MMPs in NSCLC (40-42). In addition, MMP-2 is associated with the lymphatic and vascular invasion of NSCLC, and its expression may predict a poor prognosis of early-stage patients with NSCLC (43). In addition, studies have reported that COX-2 inhibitors inhibit the expression of MMP-2 and MMP-9 in prostate cancer (44). In the present study, silencing of COX-2 resulted in decreased levels of MMP-2; however, there was no alteration in MMP-9 expression in COX-2-silenced cells (A549). These results are consistent with a previous study (45).

It is well known that VEGF is important in normal and abnormal angiogenesis, since it is involved in almost every step in the angiogenic process (46). A previous study demonstrated that COX-2 inhibitors inhibit tumor growth via an antiangiogenic mechanism (47). In addition, there is a close association between COX-2 expression and tumor angiogenesis (48). As a result, COX-2 overexpression may increase tumor blood supply and contribute to tumor growth. The present data suggested that silencing COX-2 reduced VEGF expression in A549 cells. EGFR is a member of the epidermal growth factor receptor family. Once activated, it leads to cell division, proliferation, invasion and angiogenesis (49-51). The present study observed that silencing COX-2 lead to a reduction in EGFR expression in A549 cells.

VEGF, MMP-2 and EGFR are associated with tumor angiogenesis (52-54). In the present study, the growth of cancer cells was slowed and the migration and invasion ability reduced following COX-2 silencing. These phenotypic changes may have been caused by the alterations in the expression of VEGF, MMP-2 and EGFR following COX-2 silencing. To the best of our knowledge, this is the first study to report the direct association between VEGF, MMP-2 and EGFR expression and COX-2 in lung cancer cells.

In conclusion, the present study revealed that COX-2 is very important in lung tumor growth, infiltration and metastasis via regulating VEGF, MMP-2 and EGFR expression. COX-2 may be a potential target for lung cancer prevention and treatment.

\section{Acknowledgements}

This study was financed by the Beijing Natural Science Foundation (Beijing, China; grant no. 7153162).

\section{References}

1. Torre LA, Bray F, Siegel RL, Ferlay J, Lortet-Tieulent J and Jemal A: Global cancer statistics, 2012. CA Cancer J Clin 65: 87-108, 2015.

2. Tumino R, Capocaccia R, Traina A, Madeddu A, Contrino ML and Zigon G: Estimates of cancer burden in Sicily. Tumori 99: 399-407, 2013.

3. Saver JL, Starkman S, Eckstein M, Stratton SJ, Pratt FD, Hamilton S, Conwit R, Liebeskind DS, Sung G, Kramer I, et al; FAST-MAG Investigators and Coordinators: Prehospital use of magnesium sulfate as neuroprotection in acute stroke. $\mathrm{N}$ Engl $\mathrm{J}$ Med 372: 528-536, 2015.

4. Balkwill $\mathrm{F}$ and Mantovani $\mathrm{A}$ : Inflammation and cancer: Back to Virchow? Lancet 357: 539-545, 2001.

5. Zhang L, Conejo-Garcia JR, Katsaros D, Gimotty PA, Massobrio M, Regnani G, Makrigiannakis A, Gray H, Schlienger K, Liebman MN, et al: Intratumoral T cells, recurrence, and survival in epithelial ovarian cancer. $\mathrm{N}$ Engl J Med 348: 203-213, 2003.

6. Ding Y, Tong M, Liu S, Moscow JA and Tai HH: NAD+-linked 15-hydroxyprostaglandin dehydrogenase (15-PGDH) behaves as a tumor suppressor in lung cancer. Carcinogenesis 26: 65-72, 2005.

7. Hussain SP and Harris CC: Inflammation and cancer: An ancient link with novel potentials. Int J Cancer 121: 2373-2380, 2007

8. Galon J, Costes A, Sanchez-Cabo F, Kirilovsky A, Mlecnik B, Lagorce-Pagès C, Tosolini M, Camus M, Berger A, Wind P, et al: Type, density, and location of immune cells within human colorectal tumors predict clinical outcome. Science 313: 1960-1964, 2006.

9. Whiteside TL: The tumor microenvironment and its role in promoting tumor growth. Oncogene 27: 5904-5912, 2008.

10. Denkert C, Kobel M, Berger S, Siegert A, Leclere A, Trefzer U and Hauptmann S: Expression of cyclooxygenase 2 in human malignant melanoma. Cancer Res 61: 303-308, 2001.

11. Masferrer JL, Leahy KM, Koki AT, Zweifel BS, Settle SL, Woerner BM, Edwards DA, Flickinger AG, Moore RJ and Seibert K: Antiangiogenic and antitumor activities of cyclooxygenase-2 inhibitors. Cancer Res 60: 1306-1311, 2000.

12. Hold GL and El-Omar EM: Genetic aspects of inflammation and cancer. Biochem J 410: 225-235, 2008.

13. Kokawa A, Kondo H, Gotoda T, Ono H, Saito D, Nakadaira S, Kosuge $\mathrm{T}$ and Yoshida S: Increased expression of cyclooxygenase- 2 in human pancreatic neoplasms and potential for chemoprevention by cyclooxygenase inhibitors. Cancer 91: 333-338, 2001.

14. Khuri FR, Wu H, Lee JJ, Kemp BL, Lotan R, Lippman SM, Feng L, Hong WK and Xu XC: Cyclooxygenase-2 overexpression is a marker of poor prognosis in stage I non-small cell lung cancer. Clin Cancer Res 7: 861-867, 2001.

15. Gupta S, Srivastava M, Ahmad N, Bostwick DG and Mukhtar H: Over-expression of cyclooxygenase-2 in human prostate adenocarcinoma. Prostate 42: 73-78, 2000.

16. Chen YJ, Wang LS, Wang PH, Lai CR, Yen MS, Ng HT and Yuan CC: High cyclooxygenase-2 expression in cervical adenocarcinomas. Gynecol Oncol 88: 379-385, 2003.

17. Sahin M, Sahin E and Gümüslü S: Cyclooxygenase-2 in cancer and angiogenesis. Angiology 60: 242-253, 2009. 
18. Fidler MJ, Argiris A, Patel JD, Johnson DH, Sandler A Villaflor VM, Coon J IV, Buckingham L, Kaiser K, Basu S and Bonomi P: The potential predictive value of cyclooxygenase-2 expression and increased risk of gastrointestinal hemorrhage in advanced non-small cell lung cancer patients treated with erlotinib and celecoxib. Clin Cancer Res 14: 2088-2094, 2008.

19. Van Dyke AL, Cote ML, Prysak GM, Claeys GB, Wenzlaff AS, Murphy VC, Lonardo F and Schwartz AG: COX-2/EGFR expression and survival among women with adenocarcinoma of the lung. Carcinogenesis 29: 1781-1787, 2008.

20. Banu N, Buda A, Chell S, Elder D, Moorghen M, Paraskeva C, Qualtrough D and Pignatelli M: Inhibition of COX-2 with NS-398 decreases colon cancer cell motility through blocking epidermal growth factor receptor transactivation: Possibilities for combination therapy. Cell Prolif 40: 768-779, 2007.

21. Leahy KM, Ornberg RL, Wang Y, Zweifel BS, Koki AT and Masferrer JL: Cyclooxygenase-2 inhibition by celecoxib reduces proliferation and induces apoptosis in angiogenic endothelial cells in vivo. Cancer Res 62: 625-631, 2002.

22. Jiang MC, Liao CF and Lee PH: Aspirin inhibits matrix metalloproteinase-2 activity, increases E-cadherin production and inhibits in vitro invasion of tumor cells. Biochem Biophys Res Commun 282: 671-677, 2001.

23. Li W, Wang H, Lai B, Yang X and Zhang C: The effects of interfering COX-2 gene expression on malignant proliferation of human lung adenocarcinoma A2 cell in vitro. Zhongguo Fei Ai Za Zhi 12, 100-105, 2009 (In Chinese).

24. Jungi T.W: Assay of chemotaxis by a reversible Boyden chamber eliminating cell detachment. Int Arch Allergy Appl Immunol 48: 341-352, 1975.

25. Kurosumi M: Immunohistochemical assessment of hormone receptor status using a new scoring system (J-Score) in breast cancer. Breast Cancer 14: 189-193, 2007.

26. Harris RE, Casto BC and Harris ZM: Cyclooxygenase-2 and the inflammogenesis of breast cancer. World J Clin Oncol 5 : 677-692, 2014

27. Huang QC and Huang RY: The cyclooxygenase-2/thromboxane A2 pathway: A bridge from rheumatoid arthritis to lung cancer? Cancer Lett 354: 28-32, 2014.

28. Dubois RN: Role of inflammation and inflammatory mediators in colorectal cancer. Trans Am Clin Climatol Assoc 125: 358-372; discussion 372-373, 2014.

29. Strazisar M, Mlakar V and Glavac D: The expression of COX-2, hTERT, MDM2, LATS2 and S100A2 in different types of non-small cell lung cancer (NSCLC). Cell Mol Biol Lett 14 442-456, 2009

30. Grimminger PP, Stöhlmacher J, Vallböhmer D, Schneider PM, Hölscher AH, Metzger R, Danenberg PV and Brabender J: Prognostic significance and clinicopathological associations of COX-2 SNP in patients with nonsmall cell lung cancer. J Oncol: 139590, 2009.

31. Zhu C, Liu J and Wang X: Detection of EGFR and COX-2 expression by immunohistochemical method on a tissue microarray section in lung cancer and biological significance. Zhongguo Fei Ai Za Zhi 13: 107-111, 2010 (In Chinese)

32. Li W, Yue W, Niu N, Zhang L, Zhao X, Ma L, Yang X, Zhang C, Wang $\mathrm{Y}$ and $\mathrm{Gu} \mathrm{M}$ : Expression and significance of cyclooxygenase-2 in human lung cancer. Chinese-German J Clin Oncol 13: 203-206, 2014

33. Li S, Gu Z, Xiao Z, Zhou T, Li J and Sun K: Anti-tumor effect and mechanism of cyclooxygenase-2 inhibitor through matrix metalloproteinase 14 pathway in PANC-1 cells. Int J Clin Exp Pathol 8: 1737-1742, 2015

34. Atari-Hajipirloo S, Nikanfar S, Heydari A, Noori F and Kheradmand F: The effect of celecoxib and its combination with imatinib on human HT-29 colorectal cancer cells: Involvement of COX-2, Caspase-3, VEGF and NF- $\kappa$ B genes expression. Cell Mol Biol (Noisy-le-grand) 62, 68-74, 2016.

35. Shao Y, Li P, Zhu ST, Yue JP, Ji XJ, Ma D, Wang L, Wang YJ, Zong Y, Wu YD and Zhang ST: MiR-26a and miR-144 inhibit proliferation and metastasis of esophageal squamous cell cancer by inhibiting cyclooxygenase-2. Oncotarget 7: 15173-15186, 2016

36. Kim KM, Im AR, Kim SH, Hyun JW and Chae S: Timosaponin AIII inhibits melanoma cell migration by suppressing COX-2 and in vivo tumor metastasis. Cancer Sci 107: 181-188, 2016.
37. Ho MY, Hung SW, Liang CM and Liang SM: Recombinant viral capsid protein VP1 suppresses lung cancer metastasis by inhibiting COX-2/PGE2 and MIG-7. Oncotarget 5: 3931-3943, 2014.

38. Miyata $\mathrm{Y}$, Koga S, Kanda S, Nishikido M, Hayashi $\mathrm{T}$ and Kanetake H: Expression of cyclooxygenase-2 in renal cell carcinoma: Correlation with tumor cell proliferation, apoptosis, angiogenesis, expression of matrix metalloproteinase-2, and survival. Clin Cancer Res 9: 1741-1749, 2003.

39. Sivula A, Talvensaari-Mattila A, Lundin J, Joensuu H, Haglund C, Ristimäki A and Turpeenniemi-Hujanen T: Association of cyclooxygenase- 2 and matrix metalloproteinase- 2 expression in human breast cancer. Breast Cancer Res Treat 89: 215-220, 2005.

40. Passlick B, Sienel W, Seen-Hibler R, Wöckel W, Thetter O, Mutschler W and Pantel K: Overexpression of matrix metalloproteinase 2 predicts unfavorable outcome in early-stage non-small cell lung cancer. Clin Cancer Res 6: 3944-3948, 2000

41. Gridelli C, Maione P, Airoma G and Rossi A: Selective cyclooxygenase- 2 inhibitors and non-small cell lung cancer. Curr Med Chem 9: 1851-1858, 2002.

42. Dohadwala M, Batra RK, Luo J, Lin Y, Krysan K, Pold M, Sharma S and Dubinett SM: Autocrine/paracrine prostaglandin E2 production by non-small cell lung cancer cells regulates matrix metalloproteinase-2 and CD44 in cyclooxygenase-2-dependent invasion. J Biol Chem 277: 50828-50833, 2002

43. Marrogi AJ, Travis WD, Welsh JA, Khan MA, Rahim H, Tazelaar H, Pairolero P, Trastek V, Jett J, Caporaso NE, et al: Nitric oxide synthase, cyclooxygenase 2 , and vascular endothelial growth factor in the angiogenesis of non-small cell lung carcinoma. Clin Cancer Res 6: 4739-4744, 2000.

44. Liekens S, De Clercq E and Neyts J: Angiogenesis: Regulators and clinical applications. Biochem Pharmacol 61: 253-270, 2001.

45. Wu GS, Zou SQ, Liu ZR, Tang ZH and Wang JH: Celecoxib inhibits proliferation and induces apoptosis via prostaglandin E2 pathway in human cholangiocarcinoma cell lines. World J Gastroenterol 9: 1302-1306, 2003.

46. Ghosh N, Chaki R, Mandal V and Mandal SC: COX-2 as a target for cancer chemotherapy. Pharmacol Rep 62: 233-244, 2010.

47. Menter DG, Schilsky RL and DuBois RN: Cyclooxygenase-2 and cancer treatment: Understanding the risk should be worth the reward. Clin Cancer Res 16: 1384-1390, 2010.

48. Harris RE: Cyclooxygenase-2 (cox-2) blockade in the chemoprevention of cancers of the colon, breast, prostate, and lung. Inflammopharmacology 17: 55-67, 2009.

49. Hsu JY, Chang KY, Chen SH, Lee CT, Chang ST, Cheng HC, Chang WC and Chen BK: Epidermal growth factor-induced cyclooxygenase-2 enhances head and neck squamous cell carcinoma metastasis through fibronectin up-regulation. Oncotarget 6: 1723-1739, 2015.

50. Asting AG, Farivar A, Iresjö BM, Svensson H, Gustavsson B and Lundholm K: EGF receptor and COX-1/COX-2 enzyme proteins as related to corresponding mRNAs in human per-operative biopsies of colorectal cancer. BMC Cancer 13: 511, 2013.

51. Choi S, Lim TG, Hwang MK, Kim YA, Kim J, Kang NJ, Jang TS, Park JS, Yeom MH and Lee KW: Rutin inhibits B [a] PDE-induced cyclooxygenase-2 expression by targeting EGFR kinase activity. Biochem Pharmacol 86: 1468-1475, 2013.

52. Chang CH, Huang YL, Shyu MK, Chen SU, Lin CH, Ju TK, $\mathrm{Lu} \mathrm{J}$ and Lee H: Sphingosine-1-phosphate induces VEGF-C expression through a MMP-2/FGF-1/FGFR-1-dependent pathway in endothelial cells in vitro. Acta Pharmacol Sin 34: 360-366, 2013.

53. Kim D, Dai J, Park YH, Yenwong Fai L, Wang L, Pratheeshkumar P, Son YO, Kondo K, Xu M, Luo J, Shi X and Zhang Z: Activation of EGFR/p38/HIF-1 $\alpha$ is pivotal for angiogenesis and tumorigenesis of malignantly transformed cells induced by hexavalent chromium. J Biol Chem: May 25, 2016 (Epub ahead of print).

54. Lee HC, Su MY, Lo HC, Wu CC, Hu JR, Lo DM, Chao TY, Tsai HJ and Dai MS: Cancer metastasis and EGFR signaling is suppressed by amiodarone-induced versican V2. Oncotarget 6: 42976-42987, 2015. 